\title{
Immune Activation During Pregnancy in Rats Leads to a PostPubertal Emergence of Disrupted Latent Inhibition, Dopaminergic Hyperfunction, and Altered Limbic Morphology in the Offspring: A Novel Neurodevelopmental Model of Schizophrenia
}

\author{
Lee Zuckerman', Moshe Rehavi', Rachel Nachman ${ }^{2}$ and Ina Weiner*, \\ 'Department of Psychology, Tel Aviv University, Tel Aviv, Israel; '²Department of Physiology and Pharmacology, Sackler Faculty of Medicine, Tel \\ Aviv University, Tel Aviv, Israel
}

\begin{abstract}
Prenatal exposure to infection is associated with increased liability to schizophrenia, and it is believed that such an association is mediated by the maternal immune response, in particular, the proinflammatory cytokines released by the maternal immune system, which may disrupt fetal brain development. Impaired capacity to ignore irrelevant stimuli is one of the central deficits in schizophrenia, and is manifested, among others, in loss of latent inhibition (LI), a phenomenon whereby repeated inconsequential pre-exposure to a stimulus impairs its subsequent capacity to signal significant consequences. We tested the effects of prenatal immune activation induced by peripheral administration of the synthetic cytokine releaser polyriboinosinic-polyribocytidilic acid (poly I: C) to pregnant dams, on LI in juvenile and adult offspring. Consistent with the characteristic maturational delay of schizophrenia, prenatal immune activation did not affect $\mathrm{LI}$ in the juvenile offspring, but led to $\mathrm{LI}$ disruption in adulthood. Both haloperidol $(0.1 \mathrm{mg} / \mathrm{kg})$ and clozapine $(5 \mathrm{mg} / \mathrm{kg})$ reinstated $\mathrm{LI}$ in the adult offspring. In addition, prenatal immune activation led to a postpubertal emergence of increased sensitivity to the locomotorstimulating effects of amphetamine and increased in vitro striatal dopamine release, as well as to morphological alterations in the hippocampus and the entorhinal cortex in the adult offspring, consistent with the well-documented mesolimbic dopaminergic and temporolimbic pathology in schizophrenia. These results suggest that prenatal poly I:C administration may provide a neurodevelopmental model of schizophrenia that reproduces a putative inducing factor; mimics the temporal course as well as some central abnormalities of the disorder; and predicts responsiveness to antipsychotic drugs.
\end{abstract}

Neuropsychopharmacology (2003) 28, 1778 - 1789, advance online publication, 16 July 2003; doi: I 0. I 038/sj.npp. 1300248

Keywords: prenatal immune activation; poly I: C; latent inhibition; dopamine; limbic system; schizophrenia; neurodevelopment

\section{INTRODUCTION}

An inability to ignore irrelevant stimuli is one of the key deficits described in schizophrenia (Anscombe, 1987; Kraepelin, 1919; McGhie and Chapman, 1961; Nuechterlein and Dawson, 1984). One well-established behavioral procedure that assesses organisms' capacity to ignore irrelevant stimuli is that of latent inhibition (LI), in which repeated inconsequential pre-exposure to a stimulus impairs its subsequent capacity to signal significant consequences. LI is

* Correspondence: Professor I Weiner, Laboratory of Behavioral Neuroscience, Department of Psychology, Tel Aviv University, Ramat Aviv, Tel-Aviv 69978, Israel, Tel: 9723 6408993, fax: 9723 640739I or 6409547, E-mail:weiner@post.tau.ac.il

Received 30 May 2002; revised 15 April 2003; accepted 2I May 2003 Online publication: 22 May 2003 at http://www.acnp.org/citations/ Npp0522221 I/default.pdf abolished in rats and normal humans by the psychomimetic dopamine (DA) releaser amphetamine that produces and exacerbates psychotic symptoms (Gray et al, 1992a; Weiner et al, 1984), in high-schizotypal humans (Baruch et al, 1988b; Lubow et al, 1992), and in some subsets of schizophrenia patients (Baruch et al, 1988a; Gray et al, 1992b, 1995; Rascle et al, 2001; Vaitl et al, 2002; Vaitl and Lipp, 1997). Antipsychotic drugs (APDs) reverse amphetamine-induced LI disruption in rats and normalize LI in schizophrenia patients (Baruch et al, 1988a; Weiner et al, 1996), and when given alone, potentiate LI in rats and in normal humans (Weiner et al, 1997; Williams et al, 1997). The neural substrates of LI in the rat include the limbic system and the nucleus accumbens, in line with the temporolimbic and mesolimbic DA pathology implicated in schizophrenia. Consequently, disrupted LI in the rat is considered to provide an animal model of schizophrenia 
with face, construct, and predictive validity (for reviews, see Ellenbroek and Cools, 1990; Gray et al, 1991; Moser et al, 2000; Weiner, 1990, 2000, 2003; Weiner and Feldon, 1997).

In recent years, converging evidence from epidemiological, brain imaging, and neuropathological studies has led to an increasing acceptance of the notion that at least a portion of adult schizophrenia is a neurodevelopmental disorder, whereby a brain abnormality is inherited or sustained early in life, but is not fully expressed until early adulthood (Arnold, 1999; Beckmann, 1999; Murray et al, 1992a, b; Weinberger, 1987), and this has been paralleled by increasing efforts to develop animal neurodevelopmental models of the disorder (Lipska and Weinberger, 2000). Among environmental factors that may detrimentally affect neurodevelopment, prenatal exposure to viral infection has been implicated by several large epidemiological studies, indicating that such exposure increases the risk of schizophrenia (Adams et al, 1993; Izumoto et al, 1999; Mednick et al, 1994; O'Callaghan et al, 1994; Torrey et al, 1988).

Although direct evidence linking schizophrenia to prenatal infection is lacking, studies in rodents have shown that perinatal viral infections can lead to structural brain and behavioral abnormalities considered relevant to schizophrenia. For example, it has been shown that neonatal inoculation with Cytomegalovirus, Herpes simplex virus type 1, or the bacterial endotoxin lipopolysaccharide (LPS), led in the adult offspring to disrupted prepulse inhibition (PPI), considered to model sensorimotor gating deficits in schizophrenia (Borrell et al, 2002; Engel et al, 2000; Rothschild et al, 1999). Other studies have shown that prenatal inoculation with human influenza virus and neonatal inoculation with Borna disease virus or Lymphocytic Choriomeningitis virus led to abnormal temporolimbic morphology, such as reduced thickness of the hippocampus, dentate gyrus, and entorhinal cortex (Fatemi et al, 1999; Pearce et al, 2000; Rubin et al, 1999).

The mechanisms whereby viral insults during neuroontogenesis can cause latent pathology in the CNS remain unknown, but it has been suggested that the maternal immune response, and in particular, proinflammatory cytokines released by the maternal immune system, may interfere with normal fetal brain development (Gilmore and Jarskog, 1997; Kirch, 1993; Marx et al, 2001; Nawa et al, 2000; Pearce, 2000, 2001; Waltrip et al, 1990; Wright et al, 1993). The potential role of cytokines is underscored by findings that prenatal exposure to a variety of infections has been associated with an increased incidence of schizophrenia (O'Callaghan et al, 1994; Torrey et al, 1982, 1988; Watson et al, 1984; Yolken et al, 2000), indicating that such an association may be mediated by a host response that is common to all infections (Gilmore and Jarskog, 1997; Marx et al, 2001; Nawa et al, 2000; Pearce, 2001).

The present experiments tested whether prenatal immune activation would lead to a loss of LI in the offspring and whether such a loss could be reversed by treatment with the typical APD haloperidol and the atypical APD clozapine. In addition, since it is well documented that disrupted LI is related to hyperdopaminergic function (Ellenbroek and Cools, 1990; Gray et al, 1991; Moser et al, 2000; Weiner, 1990, 2003), and given the widely accepted role of subcortical dopaminergic hyperfunction in schizophrenia
(Abi-Dargham et al, 1998; Breier et al, 1997; Laruelle et al, 1996, 1999), we assessed in the offspring a behavior known to be related to increased subcortical dopaminergic transmission, namely, locomotor response to amphetamine (Lipska et al, 1993), as well as in vitro striatal DA release.

Maternal immune activation was induced by injecting pregnant dams with the synthetic double-stranded RNA, Polyriboinosinic-Polyribocytidilic acid (poly I : C), which is commonly used to mimic viral exposure because it elicits immune responses analogous to those observed during viral infection, most notably by inducing the release of proinflammatory cytokines (Doukas et al, 1994; Kimura et al, 1994; Snell et al, 1997). Poly I : C was used because it offers two advantages compared to a viral infection: First, it elicits a nonspecific immune response, namely, induction of cytokines unaccompanied by the production of specific antibodies and viral nucleic acids; second, the effects of poly I: C are time limited (lasting approximately $48 \mathrm{~h}$ ) and thus can be precisely timed to a specific period of neurodevelopment. We administered poly I: C on gestational day (GD) 15 , a time point during the proliferation and migration of the limbic cortical neurons (Bayer and Altman, 1991; Bayer et al, 1991, 1993) ${ }^{1}$.

Since an essential feature of an animal neurodevelopmental model of schizophrenia is the capacity to mimic the maturational delay between the early neurodevelopmental insult and the emergence of its relevant consequences in early adulthood characteristic of the clinical condition, the effects of prenatal poly I: C administration on LI, in vitro DA release and amphetamine-induced hyperlocomotion were tested at prepubertal age (35 days) and at adulthood (3 months). In addition, because one of the most consistent findings of brain imaging and neuropathological studies in schizophrenia are structural and cytoarchitectonic alterations, believed to be of an early neurodevelopmental origin, in the entorhinal cortex and in the hippocampus (Arnold, 1999; Arnold et al, 1991; Beckmann, 1999; Falkai et al, 1988; Jakob and Beckmann, 1986), and given that LI depends on the integrity of these same regions (Weiner, 2003; Weiner and Feldon, 1997), we examined whether prenatal immune activation would lead to anatomical abnormalities in the hippocampus and the entorhinal cortex of the adult poly $\mathrm{I}: \mathrm{C}$ offspring.

We show that immune activation during pregnancy in rats leads in their offspring to disrupted LI, increased amphetamine-induced locomotion and increased striatal DA release, and that these abnormalities exhibit a temporal course characterizing schizophrenia, namely, they are absent at prepubertal age and emerge at adulthood. Consistent with the clinical pharmacology of schizophrenia, antipsychotic treatment (clozapine and haloperidol) alleviates the LI deficit. Also consistent with neuropathological abnormalities found in schizophrenia, we present preliminary evidence indicating that prenatal poly $\mathrm{I}: \mathrm{C}$ treatment

\footnotetext{
${ }^{1}$ Initially we injected poly I: C on GDs 13,15 , and 17. Administration on GD 13 increased the miscarriage rate and was therefore discontinued. Prior to the experiments reported here, we assessed LI in 3-month-old male offspring of dams injected with poly I:C on GD 15 or 17, and found disrupted LI for both GDs (to be reported elsewhere). Therefore, in the subsequent experiments (reported here), poly I: C was administered only on GD 15.
} 
resulted in temporolimbic abnormalities in the adult offspring.

\section{MATERIALS AND METHODS}

\section{Subjects}

Male and female Wistar juvenile (35-42 days old, weight 85$115 \mathrm{~g}$ ), or adult (3-4 months old, weight $200-450 \mathrm{~g}$ ) rats bred in our laboratory were used for the experiments. They were housed four to a cage under reversed cycle lighting with ad libitum food and water, except for 1 week prior to and during the LI experiments. All experimental protocols were carried out according to the guidelines of the Institutional Animal Care and Use Committee of Tel Aviv University.

\section{Prenatal Treatment}

Wistar rats (Harlan, Jerusalem or Tel-Aviv University Medical School) were mated at about an age of 3 months and the first day after copulation was defined as day 1 of pregnancy. On GD 15, pregnant rats were anesthetized with halothane, and given either a single intravenous injection of $4.0 \mathrm{mg} / \mathrm{kg}$ poly I: C (Sigma, Israel) dissolved in saline, or an equivalent volume of saline. Poly I: $\mathrm{C}$ caused weight loss for approximately 1 day, without significantly increasing the miscarriage rate. At birth, litters were culled to eight, composed of four males and four females. On day 21, the pups were weaned and housed four to a cage by sex and litter, and maintained undisturbed till 35 days or 3 months of age, when they were tested in LI. Juvenile male and female rats were weighed and assigned to two experimental conditions, pre-exposed (PE) or nonpre-exposed (NPE), with no more than two rats from the same litter in each experimental group. Adult male and female rats were weighed and assigned to four experimental conditions, PE-vehicle injected, PE-drug (haloperidol or clozapine) injected, NPE-vehicle injected, and NPE-drug (haloperidol or clozapine) injected, with only one rat from the same litter included in each of the experimental groups. For both ages, the male/female ratio per experimental group was as close as possible to $1: 1$.

\section{Latent Inhibition}

LI was measured in a thirst-motivated conditioned emotional response (CER) procedure by comparing the suppression of drinking to a tone previously paired with a foot shock in rats who received nonreinforced exposure to the tone prior to conditioning $(\mathrm{PE})$ and in rats for whom the tone was novel (NPE; see Weiner, 2001). The apparatus consisted of Campden Instruments rodent test chambers with a retractable bottle, each set in a ventilated soundattenuating chest. When the bottle was not present, the hole was covered by a metal lid. Licks were detected by a drinkometer circuit. The PE to-be-conditioned stimulus was a $10 \mathrm{~s}, 80 \mathrm{~dB}, 2.8 \mathrm{kHz}$ tone produced by a Sonalert module. Shock was supplied by a shock generator and scrambler set at $0.5 \mathrm{~mA}, 1 \mathrm{~s}$ duration. Equipment programming and data recording were computer controlled.
Rats were handled for about 2 min daily for 5 days prior to the beginning of the experiment. A 22-h water restriction schedule was initiated simultaneously with handling and continued throughout the experiment. During the next 5 days, rats were trained to drink in the experimental chamber for $20 \mathrm{~min}$ a day. Water in the test apparatus was given in addition to the daily ration of $2 \mathrm{~h}$ given in the home cages. The LI procedure was conducted on days 11-14 and consisted of four stages given $24 \mathrm{~h}$ apart: Pre-exposure. With the bottle removed, the PE rats received 40 tone presentations with an interstimulus interval of $40 \mathrm{~s}$, whereas the NPE rats were confined to the chamber for an identical period of time without receiving the tone. Conditioning. With the bottle removed, each rat received two tone-shock pairings given $5 \mathrm{~min}$ apart. Shock immediately followed tone termination. The first tone-shock pairing was given $5 \mathrm{~min}$ after the start of the session. After the second pairing, rats were left in the experimental chamber for an additional 5 min. Retraining. Rats were given a 15 -min drinking session as in the initial training. Test. Each rat was placed in the chamber and allowed to drink from the bottle. When the rat completed 75 licks, the tone was presented for $5 \mathrm{~min}$. The following times were recorded: time to first lick, time to complete licks $1-50$, time to complete licks $51-75$, and time to complete licks 76-100. Suppression of licking was measured using a suppression ratio, $A /(A+B)$, where $A$ is time to complete licks $51-75$ (before tone onset) and $B$ is time to complete licks $76-100$ (after tone onset). LI is manifested as a higher suppression ratio (lower suppression of drinking in response to tone presentation) of the $\mathrm{PE}$ compared to the NPE group.

\section{Spontaneous and Amphetamine-Induced Activity}

Activity was assessed in juvenile rats and in vehicle-treated adult rats who were previously tested in LI. The apparatus consisted of plastic chambers $(46 \times 57 \times 37 \mathrm{~cm})$ covered by clear Perspex lids. An infrared sensor unit (Coulbourn Instruments) was installed in the center of the front wall $22 \mathrm{~cm}$ from the side walls and $12 \mathrm{~cm}$ above the grid floor. Blind areas of the sensor (the two corners of the triangles adjacent to the sensor, $17 \times 17 \times 25 \mathrm{~cm}$ ) were blocked by clear Perspex walls, and access to the sensor was prevented by a wired fence $(10 \times 10 \times 6 \mathrm{~cm})$. Movements detected by the sensor were transmitted through an eight-channel infrared motion interface to an infrared activity monitor (Coulbourn Instruments). Data recording was computer controlled. Rats were individually placed in the activity chambers and allowed $30 \mathrm{~min}$ of free exploration, at the end of which they were returned to their home cage, injected with amphetamine, and replaced into the activity chambers for $60 \mathrm{~min}$. The number of movements performed by each rat was recorded in 6-min blocks.

\section{Drugs}

Drugs were administered i.p. in a volume of $1 \mathrm{ml} / \mathrm{kg}$. Clozapine $(5 \mathrm{mg} / \mathrm{kg}$; Novartis, Switzerland), dissolved in acetic acid and diluted with saline, or haloperidol $(0.1 \mathrm{mg} /$ $\mathrm{kg}$; Janssen, Belgium), dissolved in lactic acid and diluted with saline, were administered 30 and $60 \mathrm{~min}$, respectively, prior to the conditioning stage. No-drug controls received 
the corresponding vehicle. Amphetamine (1 mg/kg; Sigma, Israel) was dissolved in saline.

\section{In Vitro $\left[{ }^{3} \mathrm{H}\right] \mathrm{DA}$ Release}

In vitro $\left[{ }^{3} \mathrm{H}\right] \mathrm{DA}$ release was measured in striatal slices derived from juvenile (42 days) and adult rats who were previously tested in LI. Rats were decapitated, brains were rapidly removed onto ice and the striatum was sliced in two perpendicular directions with a razor blade. The slices were transferred to $5 \mathrm{ml} \mathrm{Krebs}$ buffer $(\mathrm{NaCl} 124 \mathrm{mM}, \mathrm{KCl} 5 \mathrm{mM}$, $\mathrm{CaCl}_{2} 1.2 \mathrm{mM}, \mathrm{MgSO}_{4} 1.3 \mathrm{mM}, \mathrm{KH}_{2} \mathrm{PO}_{4} 1.2 \mathrm{mM}, \mathrm{NaHCO}_{3}$ $26 \mathrm{mM}$ and D-glucose $10 \mathrm{mM})$. When $\mathrm{KCl}(25 \mathrm{mM})$-induced stimulation was tested, the $\mathrm{NaCl}$ concentration was reduced to maintain osmolarity. After dispersion of the slices with a $10-\mathrm{ml}$ glass pipette, the tissue was washed for $40 \mathrm{~min}$, with the buffer being changed every $10 \mathrm{~min}$. Slices were then incubated with $\left.5 \times 10^{-8} \mathrm{~m} \mathrm{[}{ }^{3} \mathrm{H}\right] \mathrm{DA}$ in $2.5 \mathrm{ml}$ of the same Krebs buffer and $1 \mathrm{mg} / \mathrm{ml}$ of ascorbic acid, for $30 \mathrm{~min}$. The ascorbic acid remained in the buffer for the duration of the assay. At the end of the incubation, the slices were washed for $40 \mathrm{~min}$ with three changes of buffer. Aliquots of the tissue $(80 \mu \mathrm{l}$ of the gravity-packed slices) were added to baskets with a mesh bottom ( $100 \mu \mathrm{m}$ pore size) and washed for $20 \mathrm{~min}$, with one change of the buffer, prior to the release assay. Each basket was transferred at 1-min intervals through a series of vials containing buffer until stabilization of basal $\left[{ }^{3} \mathrm{H}\right] \mathrm{DA}$ release. For stimulated release, the baskets were transferred to vials containing $\mathrm{KCl}$ at $25 \mathrm{mM}$ for $1 \mathrm{~min}$. During the procedure, the temperature was maintained at $37^{\circ} \mathrm{C}$ and $\mathrm{pH}$ at 7.3 by continuous bubbling of $95 \% \mathrm{O}_{2}$ and $5 \% \mathrm{CO}_{2}$. At the end of the release procedure, the baskets were placed in $3 \mathrm{ml}$ of $\mathrm{NaOH} 1 \mathrm{~N}$ overnight to solubilize the tissue. The next day, an aliquot of the solubilized tissue was transferred to a scintillation vial and was neutralized with $1.8 \mathrm{ml}$ of acetic acid $2 \mathrm{M}$. The radioactivity in the vials was then determined by liquid scintillation spectrometry. The fractional spontaneous and stimulated $\left[{ }^{3} \mathrm{H}\right] \mathrm{DA}$ release was calculated as the amount of radioactivity released during a given period, divided by the radioactivity present at the start of the period. The rate of basal release was defined according to the release at the last prestimulation period. KCl-stimulated release rate was calculated for the $1 \mathrm{~min}$ period of exposure to $\mathrm{KCl}$.

\section{Histology}

After the completion of behavioral testing in LI, adult rats were anesthetized with an overdose of Nembutal and perfused transcardially with $4 \%$ phosphate-buffered paraformaldehyde solution. Brains were paraffin embedded and cut serially in the coronal plane to $7-\mu \mathrm{m}$ sections. Hematoxylin and Eosin and Nissl-stained sections were examined under a light microscope. Gross morphology of the poly I:C offspring brains did not differ qualitatively from controls, thus allowing observation of analogous brain regions between control and poly I: C conditions. The hippocampal region and the entorhinal cortex were identified according to the atlas of Paxinos and Watson (1998). We have rated each region for the presence of eosinophilic soma, and have defined a region as displaying pyknotic-like neurons when $20 \%$ of at least 100 neurons displayed such morphology. The purpose of this preliminary analysis was to detect whether abnormal neuronal morphology is a consistent feature of the brains of poly I: C offspring.

\section{Data Analysis}

As initial ANOVAs yielded no significant outcomes involving the gender variable, the data of the two genders were combined for final analysis. In LI experiments, latency to first lick, times to complete licks $1-50$ and licks $51-75$, and suppression ratios were analyzed with a two-way ANOVA with main factors of pre-exposure $(0,40)$ and prenatal treatment (saline, poly I:C) (Experiment 1), or with threeway ANOVAs with main factors of pre-exposure $(0,40)$, prenatal treatment (saline, poly I:C), and drug (vehicle, clozapine/haloperidol) (Experiments 2 and 3). In DA release experiments, the percentage of release was analyzed with one-way ANOVAs with a main factor of prenatal treatment (saline, poly I:C) and a repeated measurement factor of release (basal release, KCl-induced release). Significant interactions were followed by post hoc Tukey HSD comparisons. In the activity experiments, number of movements was analyzed with a $2 \times(3) \times(5)$ ANOVA with a main factor of prenatal treatment (saline, poly I:C) and a repeated measurements factor of three 30 -min blocks (1$30 \mathrm{~min}$ before injection, 31-60 min after injection, 61$90 \mathrm{~min}$ after injection) and five 6-min segments within each 30 min block.

\section{RESULTS}

\section{Histology}

Representative photomicrographs, taken at low and high magnification, of hematoxylin and eosin-stained sections of the CA1 and the CA3 subfields of the hippocampus, the dentate gyrus, and the entorhinal cortex, from offspring of poly I:C- and saline-treated dams, are presented in Figure $1 \mathrm{~A}-\mathrm{h}$, left and right columns, respectively ( $n$ per group $=4$, each rat originating from a different litter). The brains of adult offspring of poly I: C-treated dams consistently exhibited moderate to severe cell loss compared to controls. The hippocampal CA1 region was most consistently and severely affected (see Figure 1A-a, B-b), with many of the remaining neurons exhibiting a pyknotic-like profile, as indicated by the presence of shrunken or 'condensed' neurons. In hematoxylin and eosin-stained sections, such cells exhibited intensely eosinophilic nuclei with condensed cytoplasm. Similar, but less severe, pyknotic-like neuronal profiles were observed in the dentate gyrus (see Figure 1E-e, F-f) and in the entorhinal cortex (see Figure 1G-g, H-h). In addition, in the CA3, the pyknotic cells appeared to be less shrunken (see Figure $1 \mathrm{C}-\mathrm{c}, \mathrm{D}-\mathrm{d}$ ). It is notable that the affected regions of poly I: $\mathrm{C}$ brains display both eosinophilic pyknotic-like neurons and normally appearing neurons. Very few pyknotic neurons were observed in the untreated group.

Experiment 1: The Effects of Prenatal poly I:C Administration on LI in the Juvenile Offspring

The experiment included 25 rats divided into four experimental groups in a $2 \times 2$ factorial design with main factors 

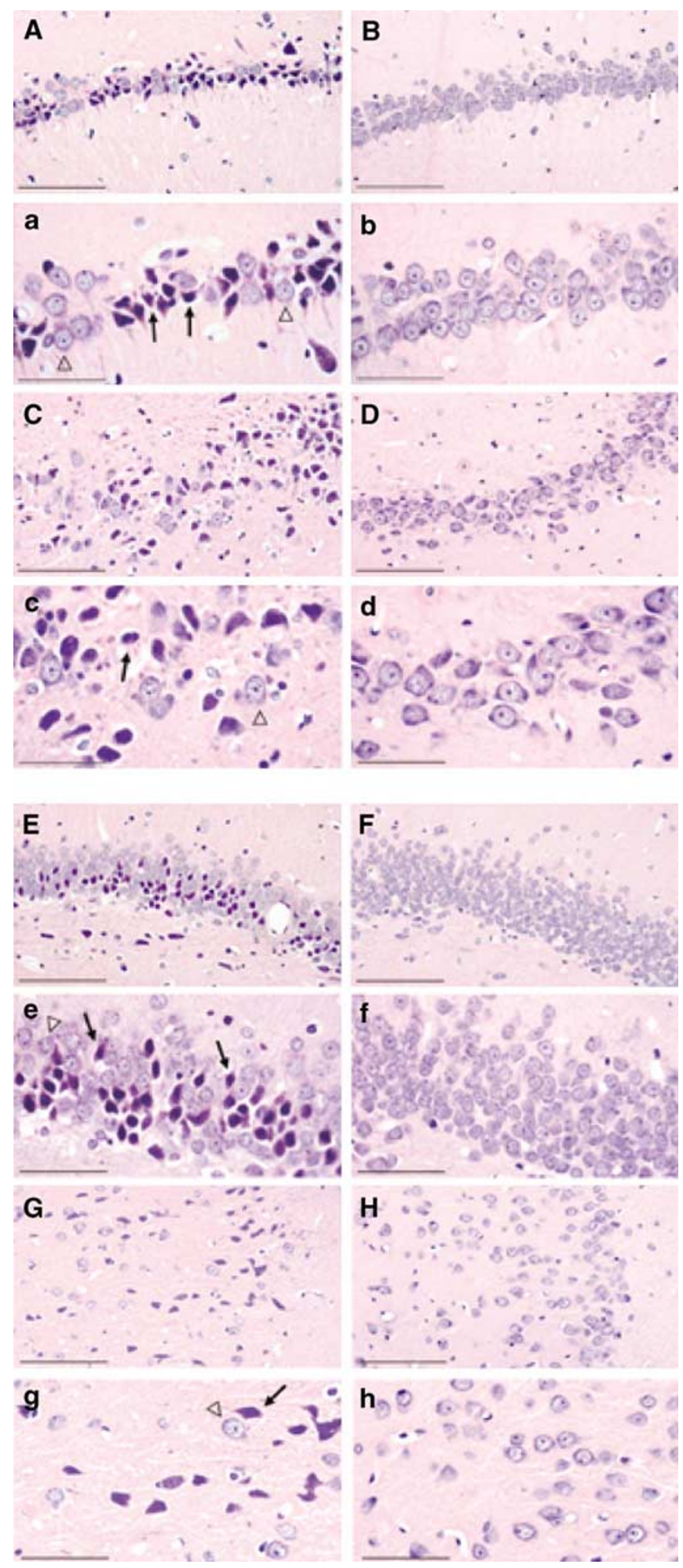

Figure I Effects of prenatal saline or poly I:C treatment on hippocampal and entorhinal cortex morphology in the adult offspring. (A-h) Representative photomicrographs of hematoxylin and eosin-stained sections from offspring of poly 1: C-treated dams (left column) and salinetreated dams (right column). Low and high magnifications of the same section are indicated with the same uppercase and lowercase letter, respectively. (A-a, B-b) Hippocampal CAI subregion; (C-c, D-d) Hippocampal CA3 subregion; (E-e, F-f) dentate gyrus; (G-g, H-h) entorhinal cortex. Neurons considered to be normal are indicated by open arrowheads, pyknotic neurons are indicated by closed arrows. Scale bars: low magnification $=50 \mu \mathrm{m}$, high magnification $=100 \mu \mathrm{m}$. of pre-exposure $(0,40)$ and prenatal treatment (saline, poly I:C) ( $n=6-7$ per group). There were no differences between the four experimental groups in latency to first lick, time to complete licks 1-50, and time to complete licks 51-75 (all $p$ 's $>0.05$ ). Figure 2 presents the mean ( \pm SEM) suppression ratios of the PE and NPE juvenile ( 35 days) offspring of saline- or poly I:C-treated dams. As can be seen, LI, that is, higher suppression ratio of the $\mathrm{PE}$ compared to the NPE group, was present in both groups. This was supported by ANOVA, which yielded only a significant main effect of pre-exposure, $\mathrm{F}(1,21)=88.23$, $p<0.0001$.

\section{Experiment 2: The Effects of Prenatal Poly I : C Administration on LI in the Adult Offspring Treated with Vehicle or Haloperidol}

The experiment included 47 rats divided into eight experimental groups in a $2 \times 2 \times 2$ factorial design with main factors of pre-exposure $(0,40)$, drug (vehicle, haloperidol), and prenatal treatment (saline, poly I:C) ( $n=5-7$ per group). There were no differences between the eight experimental groups in latency to first lick, time to complete licks 1-50, and time to complete licks 51-75 (all $p$ 's $>0.05)$. Figure 3 presents the mean $( \pm$ SEM) suppression ratios of the vehicle- or haloperidol-injected $\mathrm{PE}$ and NPE adult offspring of saline- or poly I: C-treated dams. As can be seen, LI was present in the offspring of saline-treated dams injected with either vehicle or haloperidol, as well as in haloperidol-injected offspring of poly I: C-treated dams, but was absent in saline-injected offspring of poly I: Ctreated dams. These outcomes were supported by significant main effects of pre-exposure, $\mathrm{F}(1,39)=60.56$, $p<0.0001$, prenatal treatment, $\mathrm{F}(1,39)=9.76, p<0.0034$, and drug, $\mathrm{F}(1,39)=10.68, p<0.0023$, as well as a significant pre-exposure $\times$ prenatal treatment $\times$ drug interaction, $\mathrm{F}(1,39)=5.68, p<0.022$. Post hoc comparisons assessing

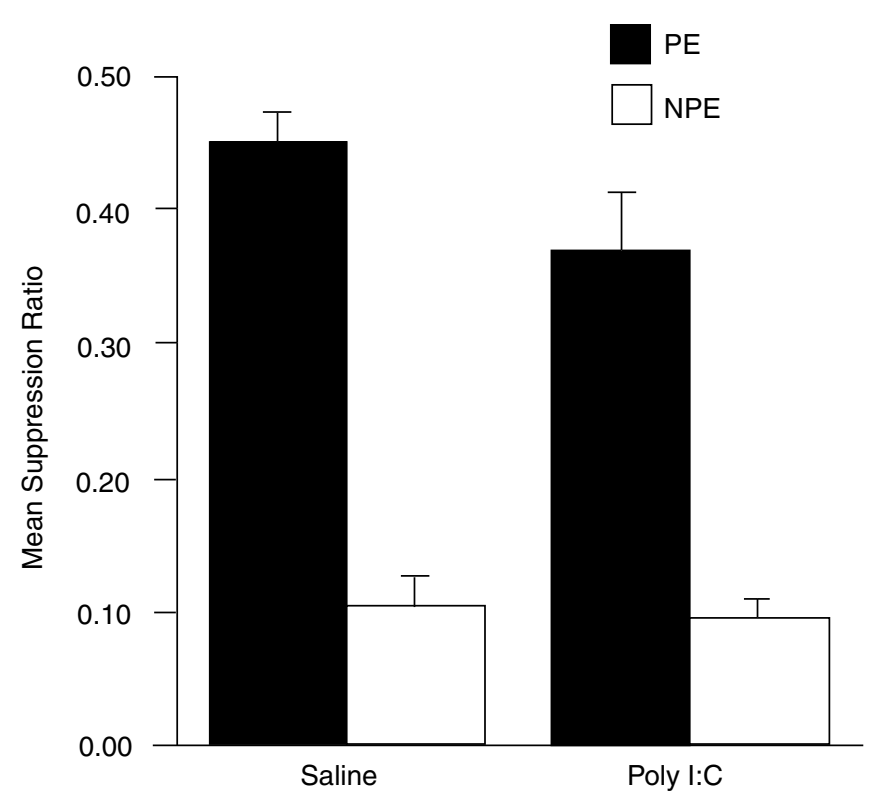

Figure 2 Mean \pm SEM suppression ratios of the PE and NPE juvenile (35 days) offspring of saline-treated and poly I: C-treated dams. 


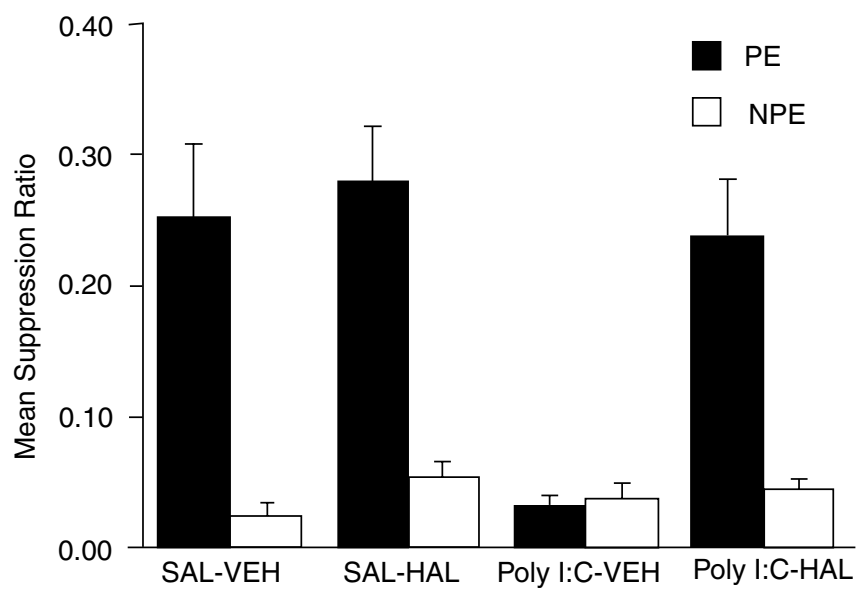

Figure 3 Mean \pm SEM suppression ratios of the vehicle- or haloperidolinjected PE and NPE adult (3 months) offspring of saline-treated dams (SAL-VEH and SAL-HAL), and poly I: C-treated dams (poly I: C-VEH and poly I: $\mathrm{C}-\mathrm{HAL}$ )

the difference between the NPE and PE groups within each condition, confirmed the existence of LI in saline-vehicle, $p<0.0001$, saline-haloperidol, $p<0.0001$ and poly I:Chaloperidol, $p<0.002$ conditions, but not in the poly I: Cvehicle condition, $p>0.05$.

Experiment 3: The Effects of Prenatal Poly I : C Administration on LI in the Adult Offspring Treated with Saline or Clozapine

The experiment included 47 rats divided into eight experimental groups in a $2 \times 2 \times 2$ factorial design with main factors of pre-exposure $(0,40)$, drug (vehicle, clozapine), and prenatal treatment (saline, poly I:C) ( $n=5-6$ per group). There were no differences between the eight experimental groups in latency to first lick, time to complete licks 1-50, and time to complete licks 51-75 (all $p$ 's $>0.05)$. Figure 4 presents the mean ( \pm SEM) suppression ratios of the vehicle- or clozapine-injected PE and NPE adult offspring of saline- or poly I : C-treated dams. As can be seen, LI was present in the vehicle- and clozapineinjected offspring of saline-treated dams, but not in the vehicle-injected offspring of poly I:C-treated dams, and clozapine-reinstated LI in the offspring of poly I : C-treated dams. These outcomes were supported by significant main effects of pre-exposure, $\mathrm{F}(1,39)=92.12, p<0.0001$, prenatal treatment, $\mathrm{F}(1,39)=18.60, p<0.0001$, and drug, $\mathrm{F}(1,39)=$ 5.72, $p<0.022$, as well as a significant pre-exposure $\times$ prenatal treatment $\times$ drug interaction $\mathrm{F}(1,39)=4.30, p<$ 0.0448. Post hoc comparisons assessing the difference between the NPE and PE groups within each condition, confirmed LI presence in the saline-vehicle, $p<0.0002$, saline-clozapine, $p<0.0002$ and poly I : C-clozapine, $p<0.0003$, conditions, but not in the poly I: C-vehicle condition $p>0.05$.

Experiment 4: The Effects of Prenatal Poly I : C Administration on In Vitro Spontaneous and Stimulated Striatal DA Release in the Juvenile Offspring

Figure 5 presents the mean percentage $( \pm$ SEM) of striatal basal and $\mathrm{KCl}$-induced $\left[{ }^{3} \mathrm{H}\right] \mathrm{DA}$ release in the juvenile $(42$

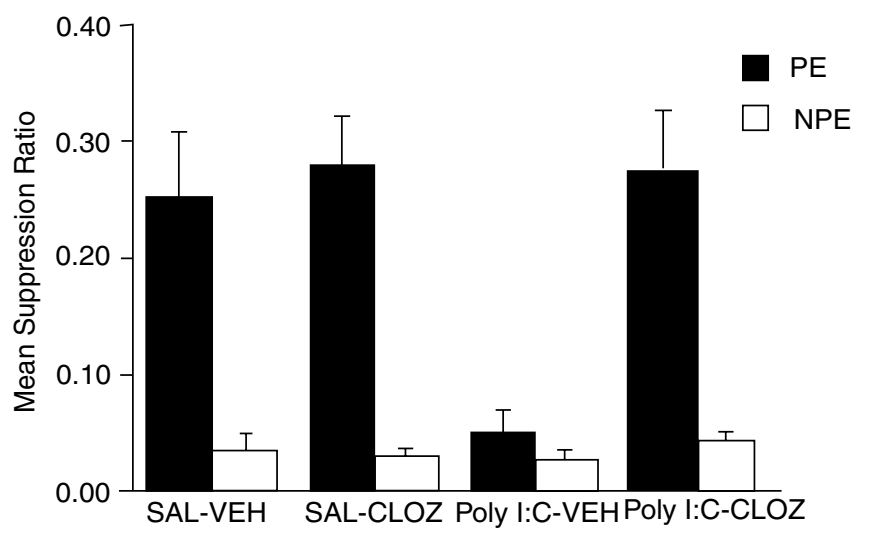

Figure 4 Mean \pm SEM suppression ratios of the vehicle- or clozapineinjected PE and NPE adult (3 months) offspring of saline-treated dams (SAL-VEH and SAL-CLOZ) and poly I: C-treated dams (poly I: C-VEH and poly I: C-CLOZ).

days) offspring of saline- or poly I: C-treated dams $(n=5$ per group). As can be seen, there were no differences between the two groups in both the basal and stimulated DA release. ANOVA yielded only a significant main effect of release, $\mathrm{F}(1,8)=893.6, p<0.0001$.

Experiment 5: The Effects of Prenatal Poly I: C Administration on In Vitro Spontaneous and Stimulated Striatal DA Release in the Adult Offspring

Figure 6 presents the mean percentage $( \pm$ SEM) of striatal basal and $\mathrm{KCl}$-induced $\left[{ }^{3} \mathrm{H}\right] \mathrm{DA}$ release in the adult offspring of saline- or poly I: C-treated dams ( $n=8-9$ per group). As can be seen, prenatal poly I : $\mathrm{C}$ treatment did not affect basal $\left[{ }^{3} \mathrm{H}\right] \mathrm{DA}$ release from the striatum of the adult rats, but $\mathrm{KCl}-$ induced $\left[{ }^{3} \mathrm{H}\right] \mathrm{DA}$ release was significantly greater in the striatum of the adult offspring of poly I: C-treated dams than in the striatum of the adult offspring of saline-treated dams. These outcomes were supported by significant main effects of prenatal treatment, $\mathrm{F}(1,15)=4.56, p<0.049$, and release, $\mathrm{F}(1,15)=380.24, p<0.0001$, as well as a significant prenatal treatment $\times$ release interaction, $F(1,15)=7.06$, $p<0.018$. The Tukey HSD post hoc comparisons yielded a significant difference between the two groups in $\mathrm{KCl}$ induced release, $p<0.037$, but not in basal release, $p>0.05$.

Experiment 6: The Effects of Prenatal Poly I : C Administration on Spontaneous and AmphetamineInduced Activity in the Juvenile Offspring

Figure 7 presents the mean $( \pm$ SEM) number of movements, in 6-min blocks, of the juvenile (40 days) offspring of saline- or poly I:C-treated dams before and after being injected with amphetamine ( $n=8$ per group). As can be seen, there were no differences between the two groups in spontaneous activity levels (first $30 \mathrm{~min}$ period), and amphetamine increased the mean number of movements in both groups in the same manner. This was supported by significant main effects of period, $\mathrm{F}(2,28)=24.10, p<0.0001$, and segment, $\mathrm{F}(4,56)=5.16$, $p<0.001$, as well as a significant period $\times$ segment 


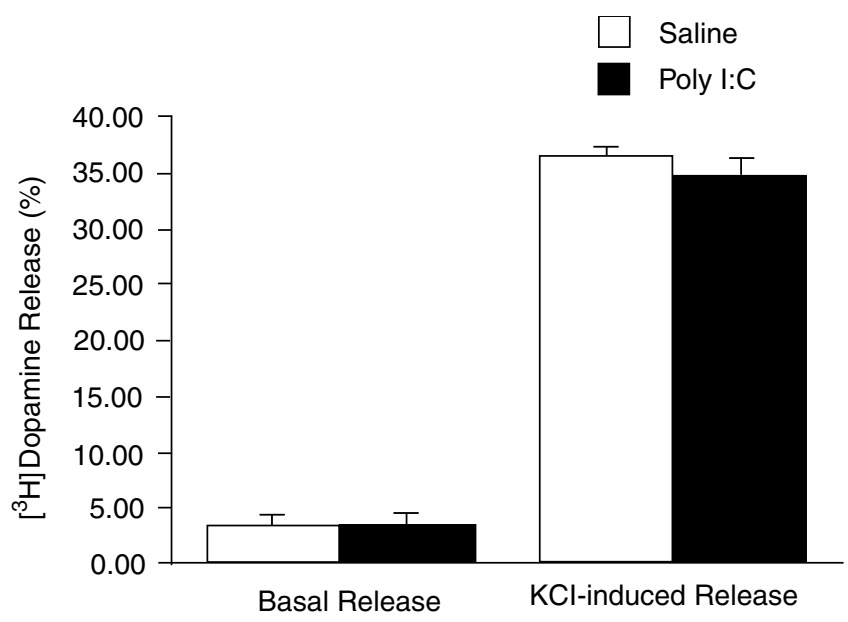

Figure 5 Mean $\pm \mathrm{SEM}$ percentage of striatal basal and $\mathrm{KCl}$-induced $\left[{ }^{3} \mathrm{H}\right] \mathrm{DA}$ release in the juvenile offspring of saline and poly I: C-treated dams.

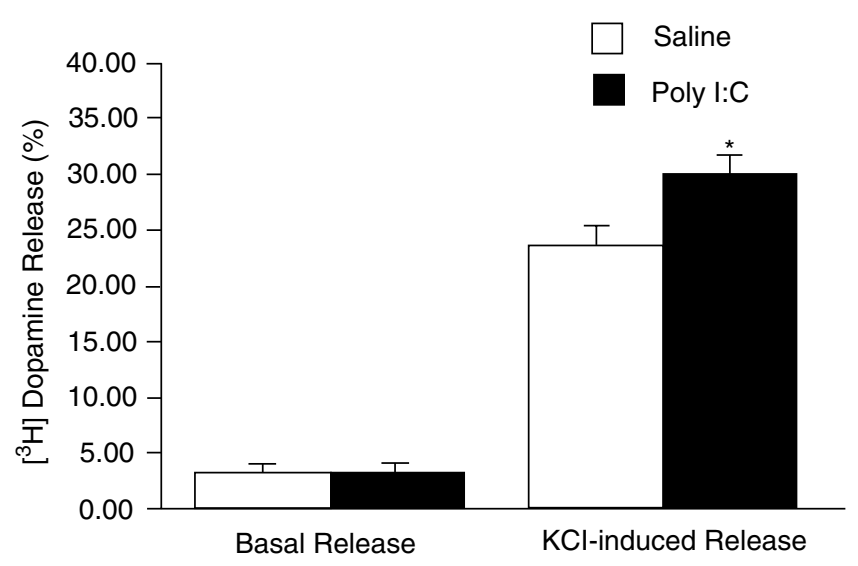

Figure 6 Mean \pm SEM percentage of striatal basal and $\mathrm{KCl}$-induced $\left[{ }^{3} \mathrm{H}\right] \mathrm{DA}$ release in the adult offspring of saline or poly I: C-treated dams.

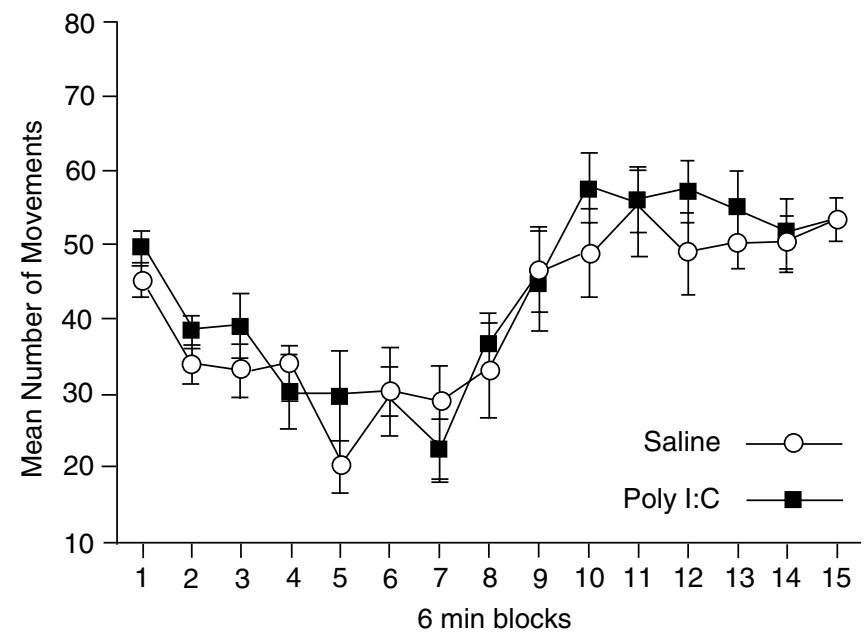

Figure 7 Mean \pm SEM number of movements, in 6-min blocks, of the juvenile offspring of saline or poly I: C-treated dams before (blocks I-5) and after (blocks 6-15) being injected with amphetamine. interaction, $\mathrm{F}(8,112)=19.82, p<0.0001$. One-way ANOVA with a main factor of prenatal treatment (saline, poly I:C) performed on the cumulative number of movements after amphetamine administration yielded no effect of prenatal treatment, $p>0.05$.

Experiment 7: The Effects of Prenatal Poly I : C Administration on Spontaneous and AmphetamineInduced Activity in the Adult Offspring

Figure 8 presents the mean ( \pm SEM) number of movements, in 6-min blocks, of the adult offspring of saline- or poly I: C-treated dams before and after being injected with amphetamine ( $n=8$ per group). As can be seen, there were no differences in spontaneous activity between the two groups. Amphetamine increased activity in both groups, but the offspring of poly I:C-treated dams were more active than the offspring of saline-treated rats. These outcomes were supported by significant main effects of period, $\mathrm{F}(2,28)=45.54, p<0.0001$, and segment, $\mathrm{F}(4,56)=2.65$, $p<0.042$, as well as a significant prenatal treatment $\times$ period interaction, $\mathrm{F}(2,28)=5.3, p<0.011$, and a significant prenatal treatment $\times$ period $\times$ segment interaction, $\mathrm{F}(8,112)=2.41, p<0.019$. One-way ANOVA with a main factor of prenatal treatment (saline, poly $\mathrm{I}: \mathrm{C}$ ) performed on the cumulative number of movements after amphetamine administration, yielded a significant main effect of prenatal treatment, $\mathrm{F}(1,14)=5.33, p<0.036$.

\section{DISCUSSION}

Thirty five days old offspring of both saline- and poly I : Ctreated dams who were preexposed to the tone exhibited less suppression of drinking during tone presentation than their NPE counterparts, namely, showed normal LI. In contrast, when tested at adulthood, the offspring of salinetreated dams showed LI, but LI was absent in the adult offspring of poly I : C-treated dams. Thus, while the juvenile offspring of poly I: C-treated dams exhibited intact capacity to ignore the previously inconsequential stimulus when it

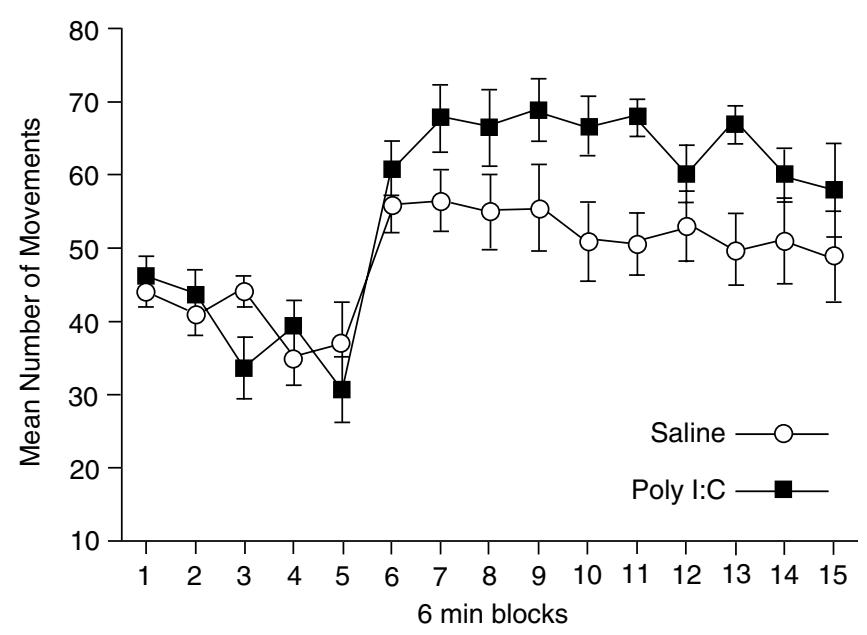

Figure 8 Mean \pm SEM number of movements, in 6-min blocks, of the adult offspring of saline or poly I: C-treated dams before (blocks I-5) and after (blocks 6-15) being injected with amphetamine. 
came to signal reinforcement, such capacity was lost in the adult offspring, so that these rats treated the irrelevant stimulus as if it were relevant.

Several previous studies have shown that LI is disrupted following various manipulations during the period of perinatal development, including postnatal restriction of environmental stimulation, maternal separation or hippocampal lesion, and prenatal stress or corticosterone administration (Ellenbroek and Cools, 1995; Grecksch et al, 1999; Shalev et al, 1998; Shalev and Weiner, 2001; Weiner et al, 1985, 1987). However, LI was assessed in these studies only in adult rats. Since a key feature of schizophrenia is a long latency between the neurodevelopmental aberration and its overt onset after puberty, an essential premise of the neurodevelopmental theory is that the emergence of symptoms is dependent on brain maturational processes that occur after puberty (Lieberman et al, 2001). If the psychosis-mimicking adult LI disruption induced by perinatal manipulations is dependent on postpubertal maturational processes, then it can be expected that LI would be normal at prepubertal age, as indeed was the case in the offspring of poly I : C-treated dams. Thus, our study further supports the critical influence of perinatal insults on LI development, and in addition demonstrates for the first time that LI abnormality exhibits a developmental course that is predicted by the neurodevelopmental theory of schizophrenia.

Consistent with the widely documented ability of APDs to reverse LI disruption and with the clinical pharmacology of schizophrenia, both the typical APD haloperidol and the atypical APD clozapine were effective in restoring the capacity of the adult offspring of poly I: C-treated dams to ignore the PE stimulus. To date, only one study showed that LI disruption following an early postnatal manipulation was reversed by APD treatment (Feldon and Weiner, 1988). The present results provide an additional demonstration that a neurodevelopmentally induced LI loss can be alleviated by antipsychotic treatment.

It is well documented that disrupted LI in the rat is related to hyperdopaminergic function (Ellenbroek and Cools, 1990; Joseph et al, 2000; Moser et al, 2000; Weiner, 1990, 2003). Therefore, LI loss in the adult offspring of poly I : C-treated dams and its reversal by both haloperidol and clozapine, which share the feature of dopaminergic blockade (Arnt and Skarsfeldt, 1998), strongly suggested that the subcortical DA system is overactive in these offspring. This was supported by the findings of greater amphetamineinduced hyperlocomotion and in vitro stimulated striatal DA release following prenatal poly I: C treatment. Moreover, these abnormalities also exhibited a maturational delay. While motor activity after amphetamine was similar in the juvenile offspring of saline- and poly I:C-treated dams, prenatal poly I:C affected such hyperactivity differentially at adulthood, so that the offspring of poly I: C-treated dams exhibited greater amphetamine-induced hyperactivity than their controls. Likewise, stimulated striatal DA release was similar in the juvenile offspring of saline- and poly I:C-treated dams, but such release was greater in the striatum of the adult offspring of poly I: Ctreated dams than in the striatum of the controls. Taken together, our results indicate that prenatal poly I:C administration leads to a delayed emergence of behavioral and neurochemical changes suggestive of increased dopaminergic responsivity. Moreover, since both disrupted LI and amphetamine-induced hyperactivity are primarily linked to excessive DA transmission in the mesolimbic system (Lipska et al, 1992; Weiner, 1990), our results may be suggestive of a maturation-dependent increased mesolimbic DA function in adult poly I: C rats.

In addition, our results showed that prenatal poly I : $\mathrm{C}$ treatment resulted in histopathological abnormalities in the CA1 and CA3 regions of the hippocampus the dentategyus and the entorhinal cortex of the adult offspring. Specifically, pyknotic-like neuronal profiles were observed in all the regions, with the CA1 being most severely affected. It is widely documented that the temporolimbic and the DA systems are intimately linked, with perturbations in the former leading to increased subcortical DA function (Csernansky et al, 1991; O’Donnell and Grace, 1998; Todd and Grace, 1999). Accordingly, lesions to limbic structures lead to increased amphetamine-induced activity and LI disruption, which is reversed by dopaminergic blockade (Gosselin et al, 1996; Lipska et al, 1992; Yee et al, 1995). Therefore, given the presence of anatomical abnormalities in the hippocampus and the entorhinal cortex of adult poly $\mathrm{I}$ : C rats, dopaminergic hyperfunction in these rats could be consequent to disrupted temporolimbic input to the DA system. However, the fact that dopaminergic function was not critically affected prior to puberty, suggests that the expression of disrupted temporolimbic input with respect to DA-related behaviors depends on a maturation-dependent interaction between the temporolimbic and dopaminergic systems, as suggested by Weinberger and Lipska (1995).

The fact that prenatal poly I:C administration led to long-term neurochemical, neuromorphological, and behavioral aberrations in the offspring indicates that poly $\mathrm{I}: \mathrm{C}$ effects were centrally mediated. Furthermore, given the $48 \mathrm{~h}$ window of poly I : $\mathrm{C}$ action, the observed abnormalities can be relatively precisely correlated with the time of neurodevelopment. As GDs $15-17$ is a time when the entorhinal cortex, and the CA1 and CA3 fields undergo neurogenesis (Bayer and Altman, 1991; Bayer et al, 1991, 1993), it is likely that poly I: C-induced maternal immune activation interfered with the normal development of these fetal sites. The precise mechanisms by which maternal immune response may affect the developing brain remain to be elucidated, but maternally generated cytokines are believed to be involved, because of the following reasons: (1) they can enter the fetal circulation and influence cytokine levels in the fetal brain; and (2) there is evidence from in vitro and in vivo studies that cytokines regulate brain development (Malek-Ahmadi, 1996; Marx et al, 2001; Medlock et al, 1993; Mehler and Kessler, 1998; Merrill, 1992; Patterson and Nawa, 1993; Rothwell and Hopkins, 1995; Urakubo et al, 2001). Particularly relevant in the present context are the findings that cytokines detrimentally affect the developing hippocampal neurons (Araujo and Cotman, 1995; Jarskog et al, 1997).

Although a comparison in relation to human gestation is not straightforward, the time window targeted here may roughly correspond to the second trimester of human pregnancy, a period during which viral insults are believed to provoke disrupted ontogenesis of the parahippocampal 
region, which may ultimately provide the neural substrate for the psychopathological phenomena associated with schizophrenia (Beckmann, 1999; Brown et al, 2000; Kunugi et al, 1995). However, while the presently observed deleterious consequences of prenatal poly I: C administration validate this method of induction as well as its timing, it remains to be determined whether such consequences are restricted to cytokine induction on GDs 15-17. Future tests should determine the effects of prenatal poly $\mathrm{I}: \mathrm{C}$ as a function of different time windows during fetal neurodevelopment.

Whatever the precise mechanisms underlying the influence of immune stimulation during pregnancy, the present findings showed that such stimulation led to a postpubertal emergence of increased striatal DA release, an increased sensitivity to locomotor-stimulating effects of amphetamine, LI impairment that is ameliorated with APD treatment, and morphological alterations in the limbic system, phenomena reminiscent of schizophrenia in terms of a temporal course (emergence in early adulthood), affected neurotransmitter system (DA hyperfunction), limbic pathology, cognitive dysfunction, and sensitivity to APDs.

Although extrapolation of data from rodent models to complex human syndromes such as schizophrenia is problematic, the phenomena observed in this study seem to be relevant to the clinical phenomenology and pharmacology. As detailed in the Introduction, LI loss is observed in rats and normal humans treated with amphetamine (Gray et al, 1992a; Weiner et al, 1984), in high schizotypal humans (Baruch et al, 1988b; Lubow et al, 1992), and in acutely psychotic schizophrenia patients (Baruch et al, 1988a; Gray et al, 1992b, 1995; Rascle et al, 2001; Vaitl and Lipp, 1997), whereas APDs potentiate LI in rats and normal humans, and restore LI in schizophrenia patients (Baruch et al, 1988a; Weiner et al, 1996; Williams et al, 1997). These results strengthen the likelihood that the LI effect observed in the two species is functionally and pharmacologically the same phenomenon, and that disrupted LI in the offspring of poly I: C-treated dams may be equivalent to disrupted LI exhibited by schizophrenia patients. The finding of increased responsivity to amphetamine and striatal DA release in the poly $\mathrm{I}: \mathrm{C}$ offspring is consistent with the widely accepted role of subcortical dopaminergic hyperfunction in schizophrenia, and in particular with the recent findings from neuroimaging studies of increased sensitivity to amphetamine and increased striatal DA release in untreated and neuroleptic naïve schizophrenics in comparison to normal controls (Abi-Dargham et al, 1998; Breier et al, 1997; Laruelle et al, 1996, 1999). Finally, the observed morphological abnormalities in the hippocampus and the entorhinal cortex in the adult poly I:C offspring are consistent with findings of morphological abnormalities described in these same regions in schizophrenia (Arnold, 1999; Beckmann, 1999; Bogerts et al, 1985; Falkai et al, 1988; Jakob and Beckmann, 1986).

Furthermore, our results suggest that prenatal poly I : Cinduced deficits may provide a model of positive symptoms of schizophrenia. It is commonly asserted that both typical and atypical APDs are effective against positive symptoms, whereas atypical APDs have higher efficacy for negative symptoms, and that therefore, an animal model that is sensitive to atypical but not typical APDs may have predictive validity for the latter condition, whereas a model that is sensitive to both classes of APDs, may have predictive validity for the former condition (Arnt and Skarsfeldt, 1998; Brunello et al, 1995; Kinon and Lieberman, 1996). Viewed in this light, our finding that poly I: Cinduced LI disruption was reversed by both haloperidol and clozapine, indicates that such disruption has predictive validity for positive symptoms. The latter is in line with clinical findings that LI tends to be disrupted in the acute stages of schizophrenia that are typically associated with predominant positive symptomatology (Baruch et al, 1988a; Gray et al, 1992b, 1995; Rascle et al, 2001), and that amphetamine challenge and increased striatal DA release in schizophrenic patients are correlated with an exacerbation of positive symptoms (Abi-Dargham et al, 1998; Breier et al, 1997; Laruelle et al, 1996, 1999). Finally, limbic system pathology has been considered particularly significant in the development of positive symptoms (Bogerts et al, 1985; Gray et al, 1991).

In conclusion, our findings suggest that prenatal administration of the synthetic cytokine inducer poly I: C may provide a neurodevelopmental model of positive symptoms of schizophrenia which: (1) reproduces a putative inducing factor; (2) mimics the characteristic maturational delay of the clinical disorder; (3) mimics a central cognitive, neurochemical, and neuropathological abnormality of the disorder; and (4) predicts responsiveness to APDs. This in turn supports the hypothesis that immune activation during pregnancy may in part be responsible for the interaction between maternal infection during pregnancy and schizophrenia (Gilmore and Jarskog, 1997; Kirch, 1993; Nawa et al, 2000; Pearce, 2001; Wright et al, 1993). Moreover, prenatal poly I: C administration may provide a unique model in terms of the study of induction at the functional level, because immune activation precisely timed to specific periods of fetal neurodevelopment may allow the characterization of critical risk periods during which immuneinduced disruption of selectively vulnerable neuronal populations/systems can lead to dysfunctional brain circuitries and postpubertal pathology relevant to schizophrenia. Although additional exogenously applied gestational insults, namely, X-ray irradiation (Mintz et al, 1998) and systemic administration of a mitotic toxin methylazoxymethanol (Fiore et al, 2000; Talamini et al, 1998), can be precisely timed to specific periods of neurodevelopment, poly $\mathrm{I}: \mathrm{C}$ administration is more etiologically relevant, because viral infections have been one of the environmental factors most often considered as predisposing to schizophrenia. Moreover, proinflammatory cytokines are elevated during additional neurodevelopmental insults associated with increased schizophrenia risk, such as ischemia and hypoxia (Marx et al, 2001). The relevance of prenatal immune-induced maldevelopment is further supported by the fact that the behavioral and biological consequences relevant to schizophrenia arise after a maturational latency. Although the model does not address the involvement of a genetic component in schizophrenia, it may be highly relevant to subgroups of schizophrenia in which environmental factors in general and gestational factors in particular are considered to play a significant role (Kirch, 1993; Murray et al, 1992a; Wright et al, 1993). 


\section{ACKNOWLEDGEMENTS}

We are indebted to Dr Raya Eilam, Dr Tamar Kadar, and Dr Holly Moore for their invaluable help with the histological assessment and to Prof. Shamgar Ben-Eliahu for his inspiration and help with prental Poly I: C treatment. We thank Novartis Switzerland and Janssen Belgium for their gift of clozapine and haloperidol, respectively. This research was partly supported by the Adams Super-Center for Brain Studies, Tel-Aviv University, and the Israel Foundations Trustees award to LZ.

\section{REFERENCES}

Abi-Dargham A, Gil R, Krystal J, Baldwin RM, Seibyl JP, Bowers M et al (1998). Increased striatal dopamine transmission in schizophrenia: confirmation in a second cohort. Am J Psychiatry 155: 761-767.

Adams W, Kendell RE, Hare EH, Munk-Jorgensen P (1993). Epidemiological evidence that maternal influenza contributes to the aetiology of schizophrenia. An analysis of Scottish, English, and Danish data. Br J Psychiatry 163: 522-534.

Anscombe F (1987). The disorder of consciousness in schizophrenia. Schizophr Bull 13: 241-260.

Araujo DM, Cotman CW (1995). Differential effects of interleukin1 beta and interleukin-2 on glia and hippocampal neurons in culture. Int J Dev Neurosci 13: 201-212.

Arnold SE (1999). Neurodevelopmental abnormalities in schizophrenia: insights from neuropathology. Dev Psychopathol 11: 439-456.

Arnold SE, Hyman BT, Van Hoesen GW, Damasio AR (1991). Some cytoarchitectural abnormalities of the entorhinal cortex in schizophrenia. Arch Gen Psychiatry 48: 625-632.

Arnt J, Skarsfeldt T (1998). Do novel antipsychotics have similar pharmacological characteristics? A review of the evidence. Neuropsychopharmacology 18: 63-101.

Baruch I, Hemsley D, Gray JA (1988a). Differential performance of acute and chronic schizophrenics in a latent inhibition task. $J$ Nerv Ment Dis 176: 598-606.

Baruch I, Hemsley DR, Gray JA (1988b). Latent inhibition and 'psychotic pronness' in normal subjects. Pers Indiv Differ 9: 777-783.

Bayer SA, Altman J (1991). Neocortical Development. Raven Press: New York.

Bayer SA, Altman J, Russo RJ, Dai XF, Simmons JA (1991). Cell migration in the rat embryonic neocortex. J Comp Neurol 307: 499-516.

Bayer SA, Altman J, Russo RJ, Zhang X (1993). Timetables of neurogenesis in the human brain based on experimentally determined patterns in the rat. Neurotoxicology 14: 83-144.

Beckmann H (1999). Developmental malformations in cerebral structures of schizophrenic patients. Eur Arch Psychiatry Clin Neurosci 249: 44-47.

Bogerts B, Meertz E, Schonfeldt-Bausch R (1985). Basal ganglia and limbic system pathology in schizophrenia. A morphometric study of brain volume and shrinkage. Arch Gen Psychiatry 42: 784-791.

Borrell J, Vela JM, Arevalo-Martin A, Molina-Holgado E, Guaza C (2002). Prenatal immune challenge disrupts sensorimotor gating in adult rats. Implications for the etiopathogenesis of schizophrenia. Neuropsychopharmacology 26: 204-215.

Breier A, Su TP, Saunders R, Carson RE, Kolachana BS, de Bartolomeis A et al (1997). Schizophrenia is associated with elevated amphetamine-induced synaptic dopamine concentrations: evidence from a novel positron emission tomography method. Proc Natl Acad Sci USA 94: 2569-2574.
Brown AS, Schaefer CA, Wyatt RJ, Goetz R, Begg MD, Gorman JM et al (2000). Maternal exposure to respiratory infections and adult schizophrenia spectrum disorders: a prospective birth cohort study. Schizophr Bull 26: 287-295.

Brunello N, Masotto C, Steardo L, Markstein R, Racagni G (1995). New insights into the biology of schizophrenia through the mechanism of action of clozapine. Neuropsychopharmacology 13: $177-213$.

Csernansky JG, Murphy GM, Faustman WO (1991). Limbic/ mesolimbic connections and the pathogenesis of schizophrenia. Biol Psychiatry 30: 383-400.

Doukas J, Cutler AH, Mordes JP (1994). Polyinosinic: polycytidylic acid is a potent activator of endothelial cells. Am J Pathol 145: 137-147.

Ellenbroek BA, Cools AR (1990). Animal models with construct validity for schizophrenia. Behav Pharmacol 1: 469-490.

Ellenbroek BA, Cools AR (1995). Maternal separation reduces latent inhibition in the conditioned taste aversion paradigm. Neurosci Res Commun 17: 27-33.

Engel JA, Zhang J, Bergstrom T, Conradi N, Forkstam C, Liljeroth A et al (2000). Neonatal herpes simplex virus type 1 brain infection affects the development of sensorimotor gating in rats. Brain Res 863: 233-240.

Falkai P, Bogerts B, Rozumek M (1988). Limbic pathology in schizophrenia: the entorhinal region - a morphometric study. Biol Psychiatry 24: 518-521.

Fatemi SH, Emamian ES, Kist D, Sidwell RW, Nakajima K, Akhter $P$ et al (1999). Defective corticogenesis and reduction in Reelin immunoreactivity in cortex and hippocampus of prenatally infected neonatal mice. Mol Psychiatry 4: 145-154.

Feldon J, Weiner I (1988). Long-term attentional deficit in nonhandled males: possible involvement of the dopaminergic system. Psychopharmacology 95: 231-236.

Fiore M, Korf J, Angelucci F, Talamini L, Aloe L (2000). Prenatal exposure to methylazoxymethanol acetate in the rat alters neurotrophin levels and behavior: considerations for neurodevelopmental diseases. Physiol Behav 71: 57-67.

Gilmore JH, Jarskog LF (1997). Exposure to infection and brain development: cytokines in the pathogenesis of schizophrenia. Schizophr Res 24: 365-367.

Gosselin G, Oberling P, Di Scala G (1996). Antagonism of amphetamine-induced disruption of latent inhibition by the atypical antipsychotic olanzapine in rats. Behav Pharmacol 7: $820-826$.

Gray JA, Feldon J, Rawlins JNP, Hemsley DR, Smith AD (1991). The neuropsychology of schizophrenia. Behav Brain Sci 14: $1-84$.

Gray NS, Hemsley DR, Gray JA (1992a). Abolition of latent inhibition by a single low dose of amphetamine in man. Psychopharmacology 107: 425-430.

Gray NS, Hemsley DR, Gray JA (1992b). Abolition of latent inhibition in acute, but not chronic schizophrenics. Neurol Psychiatr Brain Res 1: 83-89.

Gray NS, Pilowsky LS, Gray JA, Kerwin RW (1995). Latent inhibition in drug naive schizophrenics: relationship to duration of illness and dopamine D2 binding using SPET. Schizophr Res 17: 95-107.

Grecksch G, Bernstein HG, Becker A, Hollt V, Bogerts B (1999). Disruption of latent inhibition in rats with postnatal hippocampal lesions. Neuropsychopharmacology 20: 525-532.

Izumoto Y, Inoue S, Yasuda N (1999). Schizophrenia and the influenza epidemics of 1957 in Japan. Biol Psychiatry 46: 119-124.

Jakob H, Beckmann H (1986). Prenatal developmental disturbances in the limbic allocortex in schizophrenics. J Neural Transm 65: 303-326.

Jarskog LF, Xiao H, Wilkie MB, Lauder JM, Gilmore JH (1997). Cytokine regulation of embryonic rat dopamine and serotonin neuronal survival in vitro. Int J Dev Neurosci 15: 711-716. 
Joseph MH, Peters SL, Moran PM, Grigoryan GA, Young AM, Gray JA (2000). Modulation of latent inhibition in the rat by altered dopamine transmission in the nucleus accumbens at the time of conditioning. Neuroscience 101: 921-930.

Kimura M, Toth LA, Agostini H, Cady AB, Majde JA, Krueger JM (1994). Comparison of acute phase responses induced in rabbits by lipopolysaccharide and double-stranded RNA. Am J Physiol 267: R1596-R1605.

Kinon BJ, Lieberman JA (1996). Mechanisms of action of atypical antipsychotic drugs: a critical analysis. Psychopharmacology 124: 2-34.

Kirch DG (1993). Infection and autoimmunity as etiologic factors in schizophrenia: a review and reappraisal. Schizophr Bull 19: 355-370.

Kraepelin E (1919). Dementia Praecox and Paraphrenia. Robert E. Kreiger Publishing Co.: New York.

Kunugi H, Nanko S, Takei N, Saito K, Hayashi N, Kazamatsuri H (1995). Schizophrenia following in utero exposure to the 1957 influenza epidemics in Japan. Am J Psychiatry 152: 450-452.

Laruelle M, Abi-Dargham A, Gil R, Kegeles L, Innis R (1999). Increased dopamine transmission in schizophrenia: relationship to illness phases. Biol Psychiatry 46: 56-72.

Laruelle M, Abi-Dargham A, van Dyck CH, Gil R, D'Souza CD, Erdos J et al (1996). Single photon emission computerized tomography imaging of amphetamine-induced dopamine release in drug-free schizophrenic subjects. Proc Natl Acad Sci USA 93: 9235-9240.

Lieberman JA, Perkins D, Belger A, Chakos M, Jarskog F, Boteva K et al (2001). The early stages of schizophrenia: speculations on pathogenesis, pathophysiology, and therapeutic approaches. Biol Psychiatry 50: 884-897.

Lipska BK, Jaskiw GE, Chrapusta S, Karoum F, Weinberger DR (1992). Ibotenic acid lesion of the ventral hippocampus differentially affects dopamine and its metabolites in the nucleus accumbens and prefrontal cortex in the rat. Brain Res 585: $1-6$.

Lipska BK, Jaskiw GE, Weinberger DR (1993). Postpubertal emergence of hyperresponsiveness to stress and to amphetamine after neonatal excitotoxic hippocampal damage - a potential animal model of schizophrenia. Neuropsychopharmacology 9: 67-75.

Lipska BK, Weinberger DR (2000). To model a psychiatric disorder in animals: schizophrenia as a reality test. Neuropsychopharmacology 23: 223-239.

Lubow RE, Ingberg-Sachs Y, Zalstein-Orda N, Gewirtz JC (1992). Latent inhibition in low and high 'psychotic-prone' subjects. Pers Indiv Differ 13: 563-572.

Malek-Ahmadi P (1996). Neuropsychiatric aspects of cytokines research: an overview. Neurosci Biobehav Rev 20: 359-365.

Marx CE, Jarskog LF, Lauder JM, Lieberman JA, Gilmore JH (2001). Cytokine effects on cortical neuron MAP-2 immunoreactivity: implications for schizophrenia. Biol Psychiatry 50: 743-749.

McGhie A, Chapman J (1961). Disorders of attention and perception in early schizophrenia. Br J Med Psychol 34: 103-116.

Medlock ES, Kaplan DL, Cecchini M, Ulich TR, del Castillo J, Andresen J (1993). Granulocyte colony-stimulating factor crosses the placenta and stimulates fetal rat granulopoiesis. Blood 81: 916-922.

Mednick SA, Huttunen MO, Machon RA (1994). Prenatal influenza infections and adult schizophrenia. Schizophr Bull 20: 263-267.

Mehler MF, Kessler JA (1998). Cytokines in brain development and function. Adv Protein Chem 52: 223-251.

Merrill JE (1992). Tumor necrosis factor alpha, interleukin 1 and related cytokines in brain development: normal and pathological. Dev Neurosci 14: 1-10.
Mintz M, Yovel G, Gigi A, Myslobodsky MS (1998). Dissociation between startle and prepulse inhibition in rats exposed to gamma radiation at day 15 of embryogeny. Brain Res Bull 45: 289-296.

Moser PC, Hitchcock JM, Lister S, Moran PM (2000). The pharmacology of latent inhibition as an animal model of schizophrenia. Brain Res Rev 33: 275-307.

Murray RM, Jones P, O’Callaghan E, Takei N, Sham P (1992a). Genes, viruses and neurodevelopmental schizophrenia. J Psychiatr Res 26: 225-235.

Murray RM, O'Callaghan E, Castle DJ, Lewis SW (1992b). A neurodevelopmental approach to the classification of schizophrenia. Schizophr Bull 18: 319-332.

Nawa H, Takahashi M, Patterson PH (2000). Cytokine and growth factor involvement in schizophrenia - support for the developmental model. Mol Psychiatry 5: 594-603.

Nuechterlein KH, Dawson ME (1984). Information processing and attentional functioning in the developmental course of the schizophrenic disorder. Schizophr Bull 10: 160-203.

O’Callaghan E, Sham PC, Takei N, Murray G, Glover G, Hare EH et al (1994). The relationship of schizophrenic births to 16 infectious diseases. Br J Psychiatry 165: 353-356.

O'Donnell P, Grace AA (1998). Dysfunctions in multiple interrelated systems as the neurobiological bases of schizophrenic symptom clusters. Schizophr Bull 24: 267-283.

Patterson PH, Nawa H (1993). Neuronal differentiation factors/cytokines and synaptic plasticity. Cell 72(Suppl): 123-137.

Paxinos G, Watson C (1998). The rat brain in stereotaxic coordinates, 4th edition Academic Press: San Diego.

Pearce BD (2000). Viral mechanisms of schizophrenia. In: Myslobodsky MS, Weiner I (eds) Contemporary Issues in Modeling Psychopathology. Kluwer Academic Publishers: Dordrecht. pp 79-102.

Pearce BD (2001). Schizophrenia and viral infection during neurodevelopment: a focus on mechanisms. Mol Psychiatry 6: 634-646.

Pearce BD, Valadi NM, Po CL, Miller AH (2000). Viral infection of developing GABAergic neurons in a model of hippocampal disinhibition. Neuroreport 11: 2433-2438.

Rascle C, Mazas O, Vaiva G, Tournant M, Raybois O, Goudemand $M$ et al (2001). Clinical features of latent inhibition in schizophrenia. Schizophr Res 51: 149-161.

Rothschild DM, O'Grady M, Wecker L (1999). Neonatal cytomegalovirus exposure decreases prepulse inhibition in adult rats: implications for schizophrenia. J Neurosci Res 57: 429-434.

Rothwell NJ, Hopkins SJ (1995). Cytokines and the nervous system II: actions and mechanisms of action. Trends Neurosci 18: 130-136.

Rubin SA, Sylves P, Vogel M, Pletnikov M, Moran TH, Schwartz GJ et al (1999). Borna disease virus-induced hippocampal dentate gyrus damage is associated with spatial learning and memory deficits. Brain Res Bull 48: 23-30.

Shalev U, Feldon J, Weiner I (1998). Gender- and age-dependent differences in latent inhibition following pre-weaning nonhandling: implications for a neurodevelopmental animal model of schizophrenia. Int J Dev Neurosci 16: 279-288.

Shalev U, Weiner I (2001). Gender-dependent differences in latent inhibition following prenatal stress and corticosterone administration. Behav Brain Res 126: 57-63.

Snell JC, Chernyshev O, Gilbert DL, Colton CA (1997). Polyribonucleotides induce nitric oxide production by human monocyte-derived macrophages. J Leukoc Biol 62: 369-373.

Talamini LM, Koch T, Ter Horst GJ, Korf J (1998). Methylazoxymethanol acetate-induced abnormalities in the entorhinal cortex of the rat; parallels with morphological findings in schizophrenia. Brain Res 789: 293-306. 
Todd CL, Grace AA (1999). Modulation of ventral tegmental area dopamine cell activity by the ventral subiculum and entorhinal cortex. Ann NY Acad Sci 877: 688-690.

Torrey EF, Rawlings R, Waldman IN (1988). Schizophrenic births and viral diseases in two states. Schizophr Res 1: 73-77.

Torrey EF, Yolken RH, Winfrey CJ (1982). Cytomegalovirus antibody in cerebrospinal fluid of schizophrenic patients detected by enzyme immunoassay. Science 216: 892-894.

Urakubo A, Jarskog LF, Lieberman JA, Gilmore JH (2001). Prenatal exposure to maternal infection alters cytokine expression in the placenta, amniotic fluid, and fetal brain. Schizophr Res 47: 27-36.

Vaitl D, Lipp O, Bauer U, Schuler G, Stark R, Zimmermann M et al (2002). Latent inhibition and schizophrenia: Pavlovian conditioning of autonomic responses. Schizophr Res 55: 147-158.

Vaitl D, Lipp V (1997). Latent inhibition and autonomic responses: a psycholophysiological approach. Behav Brain Res 88: 85-94.

Waltrip RWd, Carrigan DR, Carpenter Jr WT (1990). Immunopathology and viral reactivation. A general theory of schizophrenia. J Nerv Ment Dis 178: 729-738.

Watson CG, Kucala T, Tilleskjor C, Jacobs L (1984). Schizophrenic birth seasonality in relation to the incidence of infectious diseases and temperature extremes. Arch Gen Psychiatry 41: $85-90$.

Weinberger DR (1987). Implications of normal brain development for the pathogenesis of schizophrenia. Arch Gen Psychiatry 44: 660-669.

Weinberger DR, Lipska BK (1995). Cortical maldevelopment, antipsychotic drugs, and schizophrenia: a search for common ground. Schizophr Res 16: 87-110.

Weiner I (1990). Neural substrates of latent inhibition: the switching model. Psychol Bull 108: 442-461.

Weiner I (2000). The latent inhibition model of schizophrenia. In: Myslobodsky MS, Weiner I (eds) Contemporary Issues in Modeling Psychopathology. Kluwer Academic Publishers: Dordrecht. pp 197-230.

Weiner I (2001). Latent inhibition. In: Crawley JN, Gerfen CR, Rogawski MA, Sibley DR, Skolnick P (eds) Current Protocols in Neuroscience. John Wiley \& Sons: New York.
Weiner I (2003). The 'two-headed' latent inhibition model of schizophrenia: modeling negative and positive symptoms and their treatment. Psychopharmacology.

Weiner I, Feldon J (1997). The switching model of latent inhibition: an update of neural substrates. Behav Brain Res 88: $11-25$.

Weiner I, Feldon J, Ziv-Harris D (1987). Early handling and latent inhibition in the conditioned suppression paradigm. Dev Psychobiol 20: 233-240.

Weiner I, Lubow RE, Feldon J (1984). Abolition of the expression but not the acquisition of latent inhibition by chronic amphetamine in rats. Psychopharmacology 83: 194-199.

Weiner I, Schnabel I, Lubow RE, Feldon J (1985). The effects of early handling on latent inhibition in male and female rats. Dev Psychobiol 18: 291-297.

Weiner I, Shadach E, Barkai R, Feldon J (1997). Haloperidol- and clozapine-induced enhancement of latent inhibition with extended conditioning: implications for the mechanism of action of neuroleptic drugs. Neuropsychopharmacology 16: 42-50.

Weiner I, Shadach E, Tarrasch R, Kidron R, Feldon J (1996). The latent inhibition model of schizophrenia: further validation using the atypical neuroleptic, clozapine. Biol Psychiatry 40: 834-843.

Williams JH, Wellman NA, Geaney DP, Feldon J, Cowen PJ, Rawlins JN (1997). Haloperidol enhances latent inhibition in visual tasks in healthy people. Psychopharmacology 133: 262-268.

Wright P, Gill M, Murray RM (1993). Schizophrenia: genetics and the maternal immune response to viral infection. Am J Med Genet 48: 40-46.

Yee BK, Feldon J, Rawlins JNP (1995). Latent inhibition in rats is abolished by NMDA-induced neuronal loss in the retrohippocampal region but this lesion effect can be prevented by systemic haloperidol treatment. Behav Neurosci 109: 227-240.

Yolken RH, Karlsson H, Yee F, Johnston-Wilson NL, Torrey EF (2000). Endogenous retroviruses and schizophrenia. Brain Res Rev 31: 193-199. 